\title{
A obrigatoriedade da pré-escola no contexto das parcerias público-privadas
}

\section{The requirement of the pre-school in the context of public-private partnerships}

\section{La obligatoria de la pre-escuela en el contexto de las asociaciones público-privado \\ Flavia de Figueiredo de Lamare ${ }^{1}$ \\ Creche da Fundação Oswaldo Cruz, Pedagoga/Tecnologista em Saúde Pública}

\begin{abstract}
Resumo: Neste texto teve-se como finalidade analisar a obrigatoriedade da préescola no Brasil (Lei n. 12.796/2013) e a sua relação com o aprofundamento da participação dos organismos internacionais e do empresariado "socialmente responsável" como formulador de estratégias de implementação de políticas educacionais na Educação Infantil. $\bigcirc$ percurso metodológico da pesquisa compreendeu análise documental e reconstrução histórica com base na análise crítica marxista que situa o tema estudado no processo de luta de classes. Os resultados mostraram que as parcerias público-privadas na Educação Infantil estão em processo de expansão e fortalecimento, relacionando eficiência dos gastos sociais e investimento na primeira infância. Assim, com argumentos advindos de economistas e de neurocientistas de empresas privadas "socialmente responsáveis", a Educação Infantil poderia ser resumida a uma etapa da educação que visa ao sucesso escolar no futuro ou a uma forma de se evitar possíveis riscos sociais consequentes da situação de iniquidade social a que as crianças estão expostas.
\end{abstract}

Palavras-chave: Educação Infantil. Políticas públicas. Empresariado. Materialismo histórico-dialético.

Abstract: The purpose of this text is to analyze the compulsory nature of preschool in Brazil (Law n. 12.796/2013) and its relation with the deepening of the participation of international organizations and "socially responsible" entrepreneurs as a formulator of strategies for the implementation of educational

Doutora em Políticas Públicas e Formação Humana pela Universidade do Estado do Rio de Janeiro; Mestre em Educação Profissional e Saúde pela Fundação Oswaldo Cruz. 
policies in Brazil Early Childhood Education. The methodological course of the research comprised documentary analysis and historical reconstruction based on the marxist critical analysis that situates the theme studied in the process of class struggle. The results showed that public-private partnerships in Early Childhood Education are in the process of expansion and strengthening, relating efficiency of social spending and investment in early childhood. Thus, with arguments coming from economists and neuroscientists of "socially responsible" private companies, Early Childhood Education would be a stage of education aimed at school success in the future or avoid possible social risks arising from the situation of social injustice to which children are exposed.

Keywords: Early Childhood Education. Public policy. Businessmen. Historicaldialectical materialism.

Resumen: Este texto tiene como finalidad analizar la obligatoriedad de la preescolar en Brasil (Ley n. 12.796/2013) y su relación con la profundización de la participación de los organismos internacionales y del empresariado "socialmente responsable" como formulador de estrategias de implementación de políticas educativas en la sociedad Educación Infantil. El recorrido metodológico de la investigación comprendió análisis documental y reconstrucción histórica con base en el análisis crítico marxista que sitúa el tema estudiado en el proceso de lucha de clases. Los resultados mostraron que las alianzas público-privadas en la Educación Infantil están en proceso de expansión y fortalecimiento, relacionando eficiencia de los gastos sociales e inversión en la primera infancia. Así, con argumentos provenientes de economistas y de neurocientistas de empresas privadas "socialmente responsables", la Educación Infantil se resumiría a una etapa de la educación que apunta al éxito escolar en el futuro o forma de evitar posibles riesgos sociales consecuentes de la situación de iniquidad social a la que los niños están expuestos.

Palabras clave: Educación Infantil. Políticas públicas. Empresariado. Materialismo histórico-dialéctico. 


\section{INTRODUÇÃO}

Entre a ideia de que a infância é sempre um momento da vida feliz e as proposições de que as crianças precisam ter "voz", há mediações que não podem estar alheias às mazelas da sociedade capitalista. Vivemos também tempos de criminalização da infância, com clamor de parte da sociedade brasileira pela redução da maioridade penal, em que se forja a real complexidade da infância.

As políticas para a Educação Infantil no Brasil têm sido marcadas pelo contexto de profundas reorganizações do mercado no que se refere à produção, em que se propaga a ideia de que o papel dessas instituições, destinadas à classe trabalhadora, deve restringir-se a espaços de capacitação socioemocional ou como forma de precaver a sociedade com gastos assistenciais futuros.

Neste texto teve-se como objetivo analisar a obrigatoriedade da préescola no Brasil (Lei n. 12.796/2013) e a sua relação com o aprofundamento da participação do empresariado "socialmente responsável" e dos organismos internacionais como formuladores de estratégias de implementação de políticas educacionais na Educação Infantil.

Nesse contexto, avaliamos alguns documentos que representam uma face das Políticas Públicas de caráter neoliberal também na Educação Infantil e o aprofundamento da participação do empresariado "socialmente responsável" como organizador de muitos documentos, estabelecendo os nexos entre as políticas gerais e as mudanças que têm ocorrido na economia política internacional nas últimas décadas. 


\section{AMENIZAÇÃO E CONTROLE DA DESIGUALDADE: UIA POLÍTICA DE EDUCAÇÃO INFANTIL}

A Educação Infantil hoje se insere no que se chama de políticas públicas para a infância, portanto, independe da troca de governo para continuar a existir, uma vez que, como afirma a Constituição Federal de 1988, é um direito subjetivo da criança (BRASIL, 1988). Ao mesmo tempo, as políticas públicas não podem ser consideradas naturais, pois correspondem a um processo de luta de classes para que existam. Essas políticas têm sido uma forma de consolidação do capitalismo pela hegemonia burguesa, que determina o padrão e o nível de proteção social que o Estado deve assumir.

Nesse contexto, é preciso apreendermos os sentidos dados à própria Educação Infantil, inseridos na discussão das ações referentes às políticas públicas. Assim, compreendê-las implica considerar a organização da economia mundial e nacional e o peso dessas políticas no sentido de assegurar um suporte à ordem sociopolítica. Essa disposição, alcançada por meio do controle das políticas sociais, tem respaldo das instituições fora do Estado, entre elas, as organizações internacionais que, além de consolidar pesquisas e consensos, apoiam políticas e programas. Logo, as políticas sociais são uma forma de interferência do Estado visando à manutenção das relações sociais de determinada formação social (HÖFLING, 2001), sempre negociadas na correlação de forças.

São as razões de ordem econômica e social as que mais têm pesado na expansão da demanda por Educação Infantil e no seu atendimento por parte do Poder Público. Como indica o Banco Mundial (BM) (2002, p. 22), "quando se considera a educação como um investimento no capital humano, é interessante estimar os retornos a este investimento", e ainda,

[...] se a educação é vista como um importante investimento no capital humano, a maior produtividade da pessoa que recebe a educação é refletida em ganhos mais altos no mercado de trabalho. $\bigcirc$ objetivo é poder traduzir os benefícios da educação pré-escolar em uma expectativa de renda futura para a criança. Com este fim, são sele- 
cionados três tipos de benefícios da pré-escola: o impacto sobre o nível de escolaridade atingido, o impacto sobre a repetência e o impacto direto da educação pré-escolar sobre o nível de renda. (BANCO MUNDIAL, 2002, p. 15).

Tendo em vista o fato de os serviços voltados às crianças menores de sete anos ainda serem escassos no Brasil, o Banco Mundial (2002) propõe intervenções informais e de baixo custo que visem ao desenvolvimento da primeira infância. Nesse caso, dados os recursos insuficientes do governo, é importante examinar os

[...] sistemas informais alternativos e [os] [...] sistemas de ONGs que podem ajudar a fortalecer, ou que podem até mesmo agir como substitutos para as creches e pré-escolas tradicionais. [...] De formato flexível e de administração mais barata que o jardim de infância formal, os programas informais podem trazer múltiplos benefícios. (BANCO MUNDIAL, 2002, p. 30-31).

Embora os representantes do BM afirmem que o custo-benefício de se investir em creche e pré-escola seja alto, não há muito incentivo para que isso ocorra. Como solução, apresentam uma proposta alternativa: o fortalecimento de ações não públicas como política para a área. Um dos desdobramentos dessa concepção é o fortalecimento da visão assistencialista e precarizada na Educação Infantil.

A influência dos organismos internacionais na educação brasileira, e especificamente na Educação Infantil, ocorre de forma negociada, mas em uma relação de subalternidade. Assim, podemos concluir que a partir dos anos 2000 as políticas para as crianças são ajustadas especialmente com o Fundo das Nações Unidas para a Infância (Unicef), a Organização das Nações Unidas para a Educação, a Ciência e a Cultura (Unesco), o BM, a Organização das Nações Unidas (ONU) e a Organização para a Cooperação e Desenvolvimento Econômico (OCDE), o que pode ser comprovado nos documentos produzidos pelo Ministério da Educação (MEC), cujas referências e "parcerias" são predominantemente estabelecidas com esses organismos e seus representantes. 
As instituições privadas e os organismos internacionais compõem esse cenário por meio de estímulos de construção de programas sociais e orientações, com consenso dos governos quanto às políticas. Nos anos 2000 , nota-se uma intensificação das políticas voltadas para a primeira infância, especialmente, após James Heckman² ganhar o Prêmio Nobel de Economia com um estudo que prova os impactos econômicos favoráveis do "investimento" nessa faixa etária. Segundo Heckman (apud NERI, 2005, p. 2), crianças que frequentam creches e pré-escolas "apresentaram na idade adulta renda mais alta e probabilidades mais baixas de prisão, de gravidez precoce e de depender de programas de transferência de renda no estado futuro." Assim, a Educação Infantil ganha centralidade, por ser compreendida pelo capital como necessária à formação de competências e "chave para a equidade", visto que o acesso às "oportunidades" sociais depende também do nível educativo das pessoas. Para Araújo (apud WEBER, 2009), ${ }^{3}$ a Educação Infantil é importante

[...] do ponto de vista de neurociência, porque o cérebro se forma muito cedo. Então, se a criança não recebe certos estímulos nessa fase em que se estabelecem certas conexões neuronais, ela dificilmente vai recuperar isso depois. Através de medições e imagens as mais modernas, fica claro que é difícil que essa criança atinja o mesmo nível de uma outra que foi submetida aos estímulos adequados. [...] Depois dos 4 anos, o sistema educacional não recupera mais. As diferenças que existem por educação da mãe ou faixa de renda não são mais reversíveis. $\bigcirc$ sistema escolar não reverte. (WEBER, 2009).

O Gráfico 1 - que apresenta a taxa de retorno por dólar investido e idade - ilustra a afirmação de Araújo (apud WEBER, 2009) e ressalta a relevância da intensificação de programas voltados à primeira infância, com o argumento de que estes oferecem maior retorno econômico à sociedade.

\footnotetext{
2 James Heckman é Professor na Universidade de Chicago.

3 Aloísio Araújo é considerado o economista brasileiro com o maior número de publicações no exterior, e é Professor e Pesquisador da Fundação Getúlio Vargas.
} 
Gráfico l - Taxa de retorno por dólar investido e idade

\section{TAXA DE RETORNO X IDADE}

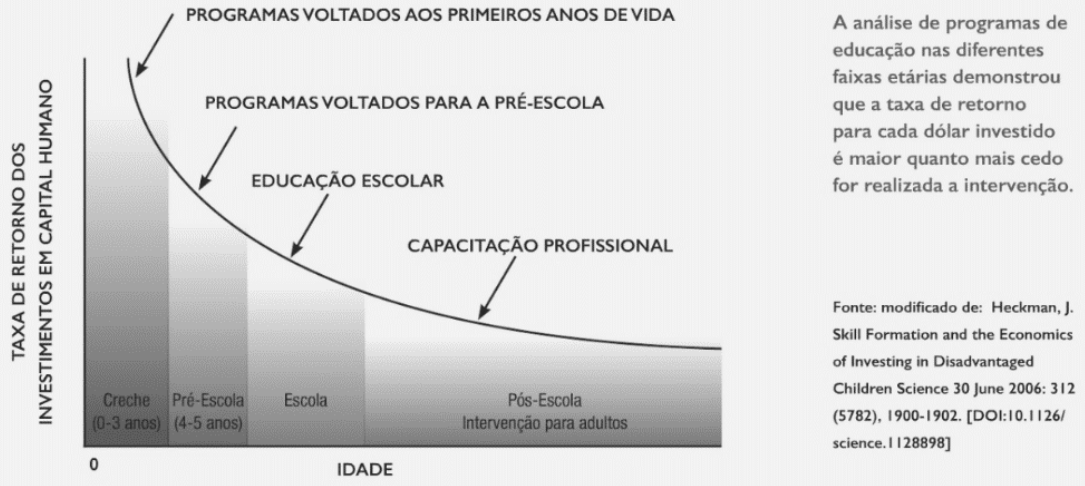

Fonte: Santos, Porto e Lerner (2014, p. 8).

Há também a articulação de interesses do BM e de outros organismos internacionais, com a burguesia brasileira, para a Educação Infantil em que se compreende desenvolvimento como capacidade individual e pessoal de representar seu mundo, sua cultura, sua realidade, sob uma perspectiva individualista e a-histórica. Em documento do Banco Mundial (2002) - cujo principal objetivo foi analisar o impacto do Desenvolvimento da Primeira Infância (DPI), particularmente da pré-escola -, afirmou-se que nessa fase há uma "intervenção efetiva no desenvolvimento da primeira infância, especialmente para a melhoria da situação de grupos mais pobres da população." (BANCO MUNDIAL, 2002, p. 7). Com isso, é evidenciada a relação entre investimento e educação, retomando os princípios da Teoria do Capital Humano (FRIGOTTO, 1998, 2009).

Intervenções importantes no início da vida são vistas como pequenos investimentos que geram altos retornos no bem-estar físico, mental e econômico durante a vida da criança e do adulto. As pesquisas também demonstram que as intervenções precoces são especialmente benéficas para crianças carentes. [...] Uma quantidade substancial de literatura de desenvolvimento sugere que um programa nacional abrangente de serviços de desenvolvimento da primeira infância pode ser uma forte arma contra a pobreza ao construir o capital humano, um dos melhores inves- 
timentos que um país pode fazer em seu desenvolvimento. (BANCO MUNDIAL, 2002, p. 8).

Na visão dos representantes do BM, a pré-escola funciona também como uma forma de controle social, uma vez que sua existência se justifica a partir de quatro bases fundamentais:

(i) os pais podem não ter informação suficiente sobre os benefícios da pré-escola, (ii) a pré-escola cria uma igualdade de oportunidades entre os cidadãos, (iii) a pré-escola aumenta a eficiência do sistema educacional e contribui para aumentar a produtividade do trabalho, e (iv) outros fatores externos positivos, tais como melhoria na saúde e nutrição. (BANCO MUNDIAL, 2002, p. 12, grifo nosso).

Alguns aspectos precisam ser ressaltados na concepção apresentada: propaga-se a ideia de que "famílias pobres" não são capazes de cuidar dos seus filhos e a solução para esse "problema" seria a pré-escola; a visão de que com a pré-escola as crianças pobres teriam a "chance" de superar a pobreza (equidade); a concepção de que a pré-escola seria capaz de oferecer bases de desenvolvimento a essas crianças, compensando, dessa forma, o déficit do lar e equilibrando as crianças "pobres" com as mais ricas. As afirmações do BM demonstram uma compreensão de pré-escola (e sua "funcionalidade") muito ouvida e propagada pelo senso comum de que o ingresso na educação escolar seria o suficiente para que o indivíduo tenha a oportunidade de sair da pobreza, de acordo com o seu esforço e rendimento. Com a "oportunidade" dada, advoga-se que cabe a cada um superar a sua "condição de pobreza". Portanto,

[...] as pré-escolas devem prioritariamente localizar-se em áreas onde há altas concentrações de pobreza [...] [pois] ao compensar déficits no lar, as intervenções de DPI [desenvolvimento da primeira infância] permitem que as crianças pobres entrem na escola com uma base de desenvolvimento mais em equilíbrio com a de seus colegas mais ricos, quebrando assim o ciclo persistente de transferência de pobreza entre as gerações. (BANCO MUNDIAL, 2002, p. 9, grifo nosso). 
Ressalta-se a visão assistencialista da pré-escola com a lógica burguesa associada a uma suposta diminuição da "pobreza" via construção de espaços de convívio ditos melhores que os com as suas famílias. Como ressaltam Costin, Banerji e Evans (2014, p. 5), "o investimento na primeira infância [...] é a coisa inteligente a ser feita do ponto de vista econômico para as crianças, bem como para as suas famílias, suas comunidades e a sociedade em geral."

A exaltação dos estudos referentes ao DPI, a fim de que se ampliem os investimentos públicos e privados nessa área, expressa uma apropriação econômica também na Educação Infantil, emergindo conceitos da neurociência relacionados à educação, com a finalidade de que se adaptem às crianças, desde a primeira infância até os valores e padrões do capital.

Reiteramos que essa concepção é pautada em uma lógica de educação da primeira infância que supervaloriza os seguintes aspectos: o homem é compreendido como um ser social somente pelo fato de viver em uma sociedade, pois o que importa é a sua individualidade que precisa ser valorizada na sua diferença e especificidade independente dos outros; a aprendizagem decorre das experiências individuais, portanto, cabe à escola oportunizar espaços para que os indivíduos desenvolvam as suas competências.

Nesse sentido, questionamos os preceitos da Lei n. 12.796/2013 (BRASIL, 2013), em que a obrigatoriedade da pré-escola se insere, tendo em vista a própria ideia de cidadania ampliada, uma vez que, de forma contraditória, o modo de produção capitalista tem efetivado concessões adequadas às circunstâncias históricas necessárias à hegemonia do capital.

\section{A OBRIGATORIEDADE DA PRÉ-ESCOLA: EDUCAÇÃO COMO “INUESTIMENTO" PARA A INCLUSÃO SOCIAL}

A ampliação da obrigatoriedade escolar de 8 para 14 anos é uma medida dos anos 2000. Essa expansão é parte dos programas de inclusão social que focalizam os chamados "grupos vulneráveis" ou "minorias", em que se compreende a pré-escola pública com a lógica burguesa como uma 
das possibilidades de redenção das questões sociais pelos indivíduos. Nesse caso, o que se afirma ser direito à inclusão precisa ser pensado à luz da responsabilização do indivíduo e da meritocracia, características da sociedade de classes. A sociedade capitalista continua sendo o horizonte, mas se agregam novos elementos a fim de que se tenha uma sociedade "harmonizada".

Dessa forma, a obrigatoriedade da Educação Infantil pode ser compreendida como uma medida compensatória necessária às consequências sociais do capitalismo contemporâneo. Como afirma Di Pierro (2001), a focalização das políticas sociais, incluindo a educação, baseia-se na lógica capitalista de que, dado os limitados recursos disponíveis, o investimento público precisa ser eficaz, o que somente seria possível por meio de ações direcionadas a pequenos grupos do território nacional ou a subgrupos populacionais para os quais esse benefício resulte em maior impacto positivo. A pré-escola estaria entre esses grupos, fundamentada, inclusive, em resultados de pesquisas realizadas na Grã-Bretanha, nos Estados Unidos e na América Latina, nas quais são avaliados os efeitos da frequência de crianças a programas de Educação Infantil (CAMPOS, 1997). Segundo esses estudos, a constância à pré-escola favorece o desempenho das crianças no Ensino Fundamental; crianças mais pobres se beneficiam mais dessa experiência. Ou seja, a Educação Infantil é uma das áreas educacionais que mais retribuiriam à sociedade os recursos nela investidos (BANCO MUNDIAL, 2002; ARAÚJO, 201 l; DENBOBA et al., 2014).

Além disso, o País também estaria cumprindo com a agenda internacional, estabelecendo uma aproximação com a Organização para a Cooperação e Desenvolvimento Econômico4 ${ }^{4}$ (OCDE) e atendendo a demandas da burguesia, uma vez que caberia à escola pública transmitir valores relacionados à inclusão social, tendo a adaptação, a flexibilidade e o individualismo como valores hegemônicos. Nesse contexto, associa-se a noção de "igualdade de oportunidades" à aplicação da regra, da justiça em que se "disputa" algo em pé de igualdade, portanto, cabendo a cada um aproveitar ou não essas "oportunidades".

\footnotetext{
4 Organização para a Cooperação e Desenvolvimento Econômico (OCDE) é a tradução de Organisation for Economic Co-operation and Development (OECD).
} 
Desse modo, justifica-se a existência da pobreza, a baixa escolaridade, entre outras, pelo fato de o sujeito não ter aproveitado as "chances" que teve na vida. Foca-se, então, no indivíduo e em políticas que "deem" oportunidade às pessoas para uma responsabilização individual, desde a mais tenra idade. A evidência dessa afirmação também pode ser encontrada no documento da OCDE, publicado no Brasil em 2002, em que se afirma:

acesso universal à ECPI [Educação e Cuidado na Primeira Infância] é visto como meio de promover a igualdade das oportunidades educativas e garantir que todas as crianças [...] possam se beneficiar de condições necessárias para estarem "prontas a aprender" quando ingressarem na escola de ensino fundamental. (ORGANIZAÇÃO PARA A COOPERAÇÃO E DESENVOLVIMENTO ECONÔ$\mathrm{MICO}, 2002)$.

Ao mesmo tempo, afirma-se que o investimento na Educação e Cuidado na Primeira Infância geraria a construção de uma nova cidadania, calcada na compreensão do mundo a partir dos interesses e valores de cada indivíduo e precavendo a sociedade de gastos com assistência social e os chamados problemas sociais.

Verbas serão destinadas a crianças consideradas em situação "de risco" a fim de estimular sua capacidade para se tornarem indivíduos autônomos e auto-suficientes, além de precaver a sociedade contra potenciais gastos advindos da dependência em relação à assistência social, à delinquência e a outros problemas sociais. (ORGANIZAÇÃO PARA A COOPERAÇÃO E DESENVOLVIMENTO ECONÔMICO, 2002, p. 60-61, grifo nosso).

É nesse contexto que a obrigatoriedade da pré-escola começa a ser desenhada no Brasil, ou seja, um cenário com prioridades que destacam o desenvolvimento de um país que pressupõe "simultaneidade entre o aumento dos investimentos, da produtividade e da competitividade e a transmissão do aumento de produtividade à renda das famílias trabalhadoras e ao lucro das empresas." (BRASIL, 2007c, p. 12). 
Para assegurar o desenvolvimento econômico elevando a produtividade e a competitividade da economia do País o Governo teve como base a "alocação de investimentos públicos e privados visando a uma organização mais equilibrada do território." (BRASIL, 2007c, p. 40). O princípio utilizado para essa meta e as outras previstas no documento de planejamento do Governo é o de um Estado na direção do processo, ou seja, induzindo as políticas públicas, mas sendo efetivadas pelo empresariado organizado.

É importante destacar que a educação escolar destinada à classe trabalhadora nesse período passa a ser fundamental para a "construção" de um novo homem, ou seja, um sujeito que se comprometa, que se solidarize, que participe de grupos, de associações em prol de um "mundo melhor", mas que tenha como cerne as questões individuais e não as coletivas. Com isso, objetiva-se a conformação do conjunto de trabalhadores, desde a infância, à cultura hegemônica, tanto do ponto de vista técnico quanto do ponto de vista ético-político.

$\bigcirc$ aumento da obrigatoriedade escolar no Brasil ocorreu com a aprovação da Emenda Constitucional (EC) n. 59/2009, que determina que até 2016 os sistemas de ensino ofereçam "Educação Básica obrigatória e gratuita dos 4 aos 17 anos de idade." (BRASIL, 2009). Com isso, o que seria a ampliação de um direito (a obrigatoriedade da Educação Básica é também uma luta progressista) acaba, do ponto de vista legal, circunscrevendo-se a uma medida que vincula a expansão da educação à incapacidade das famílias de cuidarem de seus filhos, cabendo, portanto, à pré-escola a socialização e a inclusão social. Nesse sentido, o que é pensado como direito à inclusão e papel do Estado é proposto como "responsabilidade individual de não se deixar excluir." (GARCIA, 2014, p. 108).

No Relatório de Avaliação da Política de Educação Infantil no Brasil, representantes do MEC afirmam que:

Brasil pretende alcançar os níveis econômicos e sociais das sociedades industriais avançadas. Para tanto, há dois requisitos essenciais: uma elevada capacidade de participar da economia do conhecimento e um alto grau de coesão social. A educação infantil fornece uma sólida base 
de aprendizado para a vida toda e para a sociedade do conhecimento. $\bigcirc$ acesso universal à educação infantil é um elemento fundamental numa sociedade mais coesa. (MINISTÉRIO DA EDUCAÇÃO; SECRETARIA DE EDUCAÇÃ $\bigcirc$ BÁSICA, 2009b, grifo nosso).

Portanto, a principal justificativa oficial apresentada como Avaliação da Política de Educação Infantil no Brasil se relaciona à questão econômica, ao fato de essa etapa da educação fornecer elementos aos indivíduos para que vivam de maneira coesa, por meio do oferecimento de uma base de aprendizado. No entanto, a demanda por creches deve ser vista pela diversificação do atendimento. ${ }^{5}$

Afirma-se, ainda, que a intenção de se expandirem as creches por essas parcerias se deve ao fato de que não se corra o risco de "aumentar as disparidades e aprofundar a pobreza". O conceito de pobreza é, então, ressaltado como justificativa para a ausência do Estado no que se refere à ampliação da oferta de creches. Explicita-se a transferência de verbas públicas para a iniciativa privada como solução para o problema da qualidade:

governo poderia oferecer dinheiro e diversas formas de apoio, especialmente para infraestrutura, a fim de ajudar essas entidades a se manter ou a criar serviços, desde que se registrem e aceitem monitoramento de seus padrões de qualidade. [...] $\bigcirc$ governo deveria destinar recursos para incentivar esse tipo de entidade e ajudar a pagar pela melhoria da qualidade. (MINISTÉRIO DA EDUCAÇÃO; SECRETARIA DE EDUCAÇÃO BÁSICA, 2009b, p. 69).

No Fundo de Manutenção e Desenvolvimento da Educação Básica e de Valorização dos Profissionais da Educação (Fundeb), em 2006, estava prevista a inclusão de matrículas privadas em creches de forma permanente. A ideia era que houvesse uma expansão no número de vagas nas creches, não por meio do aumento no atendimento em creches públicas, mas por intermédio de parcerias com instituições privadas (categorizadas como comunitárias,

5 ○ que inclui espaços não escolares e com diferentes fontes de financiamento. 
filantrópicas ou confessionais). Assiste-se, mais uma vez, ao Poder Público financiando a iniciativa privada.

O Fundeb (1998-2006) foi criado pela Emenda Constitucional n. 53/2006 (BRASIL, 2006) e regulamentado pela Lei n. 11.494/2007 (BRASIL, 2007c) e pelo Decreto n. 6.253 (BRASIL, 2007b), em substituição ao Fundo de Manutenção e Desenvolvimento do Ensino Fundamental e de Valorização do Magistério (Fundef). Em vigor desde 01 de janeiro de 2007, o Fundeb é uma proposta de financiamento da Educação Básica para assegurar o acesso à educação a um maior número de pessoas e teve importante incidência da sociedade civil organizada em seu processo de discussão e aprovação. Foi apresentado à população como uma política mais incisiva da União, visando a atender a todos os níveis, etapas e modalidades de ensino, pretendendo, dessa forma, corrigir as falhas do Fundef. Nessa perspectiva, esse Fundo foi divulgado como a grande solução para os males da educação. Entretanto, segundo Davies (2006, p. 3):

\begin{abstract}
Se ele [Fundeb] fosse tão importante para o governo, este teria encaminhado a sua PEC em 2003, quando teve força política e pressa inclusive para aprovar a reforma da previdência pública, não em junho de 2005, quando ficou acuado com o escândalo do mensalão. Por isso, é provável que o governo tenha proposto o Fundeb em 2005, não porque estivesse seriamente preocupado em "revolucionar" a educação, mas porque quisesse apenas melhorar sua imagem desgastada e recuperar a iniciativa política. [...] em síntese, o Fundeb, assim como o Fundef, é apenas um mecanismo de redistribuição de parte significativa dos recursos já vinculados à educação dos estados e municípios, trazendo pouquíssimos novos (apenas a complementação federal) para o sistema educacional como um todo.
\end{abstract}

Previsto para 14 anos de vigência, esse Fundo tem como mecanismo de distribuição de recursos uma lógica parecida com a utilizada pelo Fundef. Há uma captação de recursos pelos estados e municípios e uma complementação da União de acordo com o número de matrículas na Educação Básica. Novos impostos foram incorporados ao Fundeb, mas continuam de fora o Imposto Predial Territorial Urbano (IPTU), o Imposto Sobre Serviços (ISS) e o Imposto Sobre Transmissão de Bens Intervivos (ITBI) (SOUSA JUNIOR, 2007). 
○álculo para a distribuição de recursos no Fundeb ocorre a partir do total de alunos da Educação Básica presencial, pelo censo escolar no ano anterior. Desse modo, os recursos são distribuídos de acordo com as matrículas das etapas ou modalidades de ensino. Em muito, pelas reivindicações da sociedade civil organizada (inclusive entidades que em muitos momentos se mostram representes do empresariado - Figura 2), no movimento contraditório característico do capitalismo (HARVEY, 2016), conseguiu-se limitar a inclusão das matrículas de pré-escola de entidades filantrópicas, confessionais e comunitárias conveniadas aos quatro primeiros anos após a aprovação da lei, embora esse dispositivo tenha sido flexibilizado posteriormente.

Embora não se vincule diretamente à obrigatoriedade escolar, o Fundeb dá condições contábeis a essa expansão. Nesse caso, a obrigatoriedade estaria associada ao oferecimento de oportunidades iguais "a todos", em que as políticas educacionais devem se sustentar na premissa da "inclusão social". Diante disso, quanto mais cedo a criança for matriculada na escola, maior a chance de se prevenirem "problemas sociais". Tal ponto de vista é ressaltado por Cunha e Heckman (201 1, p. 11 ):

Recentes estudos sobre o desenvolvimento humano mostram que as pessoas são diferentes em várias habilidades, e que estas habilidades explicam uma grande parte da variação interpessoal no sucesso econômico e social, diversidade que se manifesta na mais tenra idade. A família desempenha um papel crucial na formação dessas habilidades, pois fornece tanto os genes quanto o meio ambiente com os quais tais habilidades são determinadas. Algumas famílias não conseguem criar ambientes propícios e isso tem resultados nefastos para os seus filhos. No entanto, vários estudos mostram que é possível compensar parcialmente os ambientes adversos se investimentos de alta qualidade forem feitos suficientemente cedo na vida da criança.

É em um contexto de ampliação de potencialidades individuais que, em 2013, é feita a alteração da LDB n. 9.394 (BRASIL, 1996) por meio da Lei n. 12.796 (BRASIL, 2013). Sua relação com a necessidade de formação de sujeitos visando à produtividade econômica e à adaptabilidade à sociedade pode ser vista na Figura 1 que elucida essa questão enfocando, ainda, o discurso do 
potencial de cada indivíduo. Para Andre e Costa (2004, p. 47), "trata-se de uma educação que reconheça e desenvolva seus potenciais, empoderandoas a agir prepositivamente sobre as questões relacionadas à descoberta de si mesmas, ao convívio e ao mundo ao seu redor."

Figura 1 - Quatro aprendizagens da perspectiva do desenvolvimento do potencial das pessoas

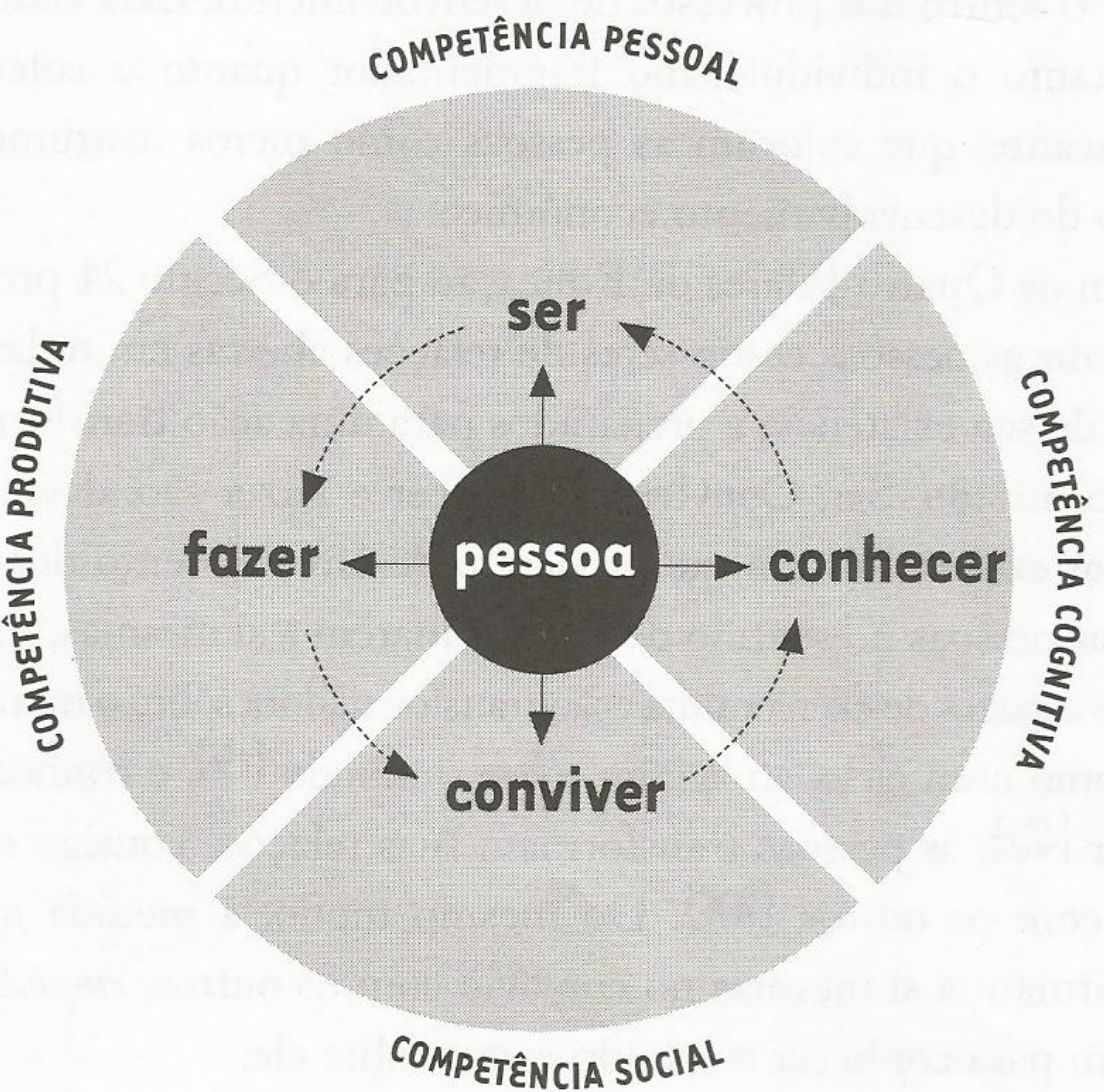

Fonte: Andre e Costa (2004, p. 46).

A figura expressa uma concepção de homem, em que o aspecto psicológico determinaria as competências para a sua ação no mundo. Deslocase, com isso, o foco dos processos educativos dos conteúdos disciplinares para o 
sujeito que aprende - ou não aprende - tendo como princípio o direito a aprender a partir de uma concepção hegemônica de mundo e de formação baseada na adaptação e na necessidade de "convivência humana", pela naturalização das desigualdades (RAMOS, 2001). Entretanto, como ensina Gramsci (2013, p. 262), a "'natureza' humana não reside dentro do indivíduo, mas na unidade do homem e das forças materiais: portanto, a conquista das forças materiais é uma maneira - e a mais importante - de conquistar a personalidade."

Do mesmo modo que para Marx e Engels (2007), os quais afirmaram que a maneira como os homens produzem sua subsistência depende dos meios concretos de que dispõem - portanto, que a natureza dos indivíduos depende das condições materiais determinantes da produção -, também para Gramsci (2013) não existe indivíduo isolado em suas subjetividades (como algo abstrato e genérico universalmente), mas como um ser dentro de uma realidade social concreta, interligado a outros sujeitos. Com isso, não seria possível existir uma "pessoa" desvinculada da realidade social, completa em si mesma; o homem é interação, síntese entre passado e a potencialidade do futuro. Diante disso, para Gramsci (2013, p. 244-245),

[...] o problema do que seja o homem é sempre, portanto, o chamado problema da "natureza humana", ou também o do chamado "homem em geral", isto é, a tentativa de criar uma ciência do homem (uma filosofia) que parta de um conceito inicialmente "unitário", de uma abstração na qual se possa conter todo o "humano". [...] A afirmação de que a "natureza humana" é o "conjunto das relações sociais" é a resposta mais satisfatória porque inclui a ideia do devir: o homem "devém", transforma-se continuamente com as transformações das relações sociais; e, também porque nega o "homem em geral": de fato, as relações sociais são expressas por diversos grupos de homens que se pressupõem uns aos outros, cuja unidade é dialética.

A obrigatoriedade da pré-escola converge com a falsa ideia de que, no mundo, hoje, existe oportunidade para todos, o que faz com que seja gerada a sensação de fracasso, de autoculpabilização. Não podemos dissociar a natureza da educação escolar do trabalho na sociedade capitalista. 
Ressaltamos que a obrigatoriedade da pré-escola não está associada a uma mudança estrutural, ou seja, essa ampliação, na lei, ocorre de modo precarizado, à medida que, por exemplo, não há uma previsão de formação para os trabalhadores que atuarão com esse segmento para além do que estava posto na LDB de 1996 - nível médio na modalidade normal.

A obrigatoriedade da pré-escola relaciona-se mais a uma política de programas focalizados - sob a orientação consentida dos organismos internacionais que versa sobre uma sociedade harmoniosa e coesa, a fim de que se mantenha a hegemonia capitalista - direcionados a uma população definida nacional e internacionalmente com padrões de pobreza do que a uma conquista social. Assim, a obrigatoriedade aparece sob o princípio do direito, mas, na realidade, pauta-se na produtividade econômica e na necessidade de coesão social.

\section{EDUCAÇÃO INFANTIL E CONSTRUÇÃO DE HEGEMONIA PARA O CAPITAL}

Em reportagem publicada no jornal Valor Econômico, do dia 28 de agosto de 2016, afirma-se que as parcerias público-privadas serão estendidas para setores como esgoto, penitenciárias, hospitais e creches com o objetivo de comprar vagas para as crianças e "racionalizar" os gastos públicos (GOES; ROSAS, 2016). Com isso, assume-se a participação, a organização e a direção do empresariado nas políticas de Educação Infantil, fato este evidenciado na análise dos documentos para essa faixa etária no período de 2003 a 2010 (LAMARE, 2016).

Cláudia Costin faz parte de um grupo de intelectuais que segue a doutrina do mercado e, por isso, tem atuado estrategicamente com diferentes funções na construção do pensamento educacional no País. Ela foi Ministra da Administração e Reforma do Estado do Governo Fernando Henrique Cardoso; atuou entre 2000 e 2001 como Gerente da América Latina na área do setor público e combate à pobreza no BM; de 2003 a 2005 foi Secretária de Cultura do Estado de São Paulo; em 2005, foi Vice-presidente da Fundação Victor Civita; em 2009, Secretária de Educação no Município do Rio de Janeiro; e, em 
2014, voltou ao BM como Diretora global de Educação. Além disso, atuou no Comitê Técnico de criação do Movimento Todos pela Educação (TPE).

○ trabalho de intelectuais como Cláudia Costin materializa o fenômeno da mundialização das relações sociais capitalistas no neoliberalismo, disseminando diversas formas de pensar, sentir e agir necessárias à perpetuação e à manutenção da hegemonia burguesa. Destacamos, entretanto, que esse processo é antagônico, por isso há contradições, há resistência. Cláudia Costin foi convidada, em 2012, pelo Ministro Aloísio Mercadante para assumir a Secretaria de Educação Básica (SEB) do MEC, mas com a mobilização de pesquisadores, professores, estudantes e suas entidades representativas foi lançado o abaixo-assinado "Cláudia Costin, não!", e ela não assumiu o cargo.

É justamente no processo de redefinição da política neoliberal ocorrida no Estado brasileiro nos anos 2000 que a burguesia intensifica a "defesa" por um maior número de vagas na escola pública (não necessariamente estatal) e a necessidade de associar medidas econômicas a outras de cunho social como: equidade, redução da pobreza, direitos das mulheres, dos negros, das crianças. Com isso, aprofundou-se a segmentação e a focalização existentes nas políticas, fragilizando-as ainda mais.

Com o compromisso global Educação para Todos, firmado em Jontien (UNESCO, 1998), o preceito de "educação ao longo da vida" foi amplamente disseminado e a educação das crianças pequenas tem sido citada e discutida. Entretanto, a Educação Infantil continua sendo tratada como uma forma de sucesso escolar no futuro, pelo desenvolvimento de competências e habilidades nessa etapa da vida, evitando riscos sociais consequentes da situação de iniquidade a que as crianças da escola pública estão expostas.

Atualmente, duas importantes organizações atuam como aparelhos privados de hegemonia no campo da Educação Infantil: a Rede Nacional Primeira Infância (RNPI) e a Fundação Maria Cecília Souto Vidigal (FMCSV). Essa Fundação é uma das principais responsáveis pela tradução e divulgação de textos e estudos sobre desenvolvimento infantil, tendo como eixos de atuação a "articulação, as práticas e a gestão do conhecimento", o que ocorre pelo estabelecimento de "parcerias com o Poder Público, a iniciativa privada 
e a sociedade civil para ampliar a abrangência e o impacto das intervenções sociais que realiza e das ações de conscientização dos temas relativos à Primeira Infância." (FUNDAÇÃO MARIA CECILIA SOUTO VIDIGAL, 2014).

A FMCSV foi criada em 1965, pelo banqueiro Gastão Eduardo de Bueno Vidigal e sua esposa, com o objetivo de incentivar a pesquisa e o conhecimento no campo da hematologia, após o falecimento de sua filha aos 13 anos de idade, vítima de leucemia. Como uma entidade familiar de caráter privado, sem fins lucrativos, em 2001 os filhos e netos do fundador reveem a atuação da Fundação com a ideia de focar o desenvolvimento infantil de forma mais ampla. Em 2005, a Fundação ampliou sua atuação tendo como áreas prioritárias a saúde, a educação e o meio ambiente, a partir da constatação de que "as experiências nos primeiros anos de vida são determinantes para o crescimento e o desenvolvimento da criança e da sociedade."

A RNPI, formada em 2007, tem se mostrado uma importante interlocutora, em diferentes níveis, nas políticas para crianças de até seis anos. Essa Rede tem organizado seminários e encontros que visam a

[...] uma articulação nacional de organizações da sociedade civil, do governo, do setor privado, de outras redes e de organizações multilaterais que atuam, direta ou indiretamente, pela promoção e garantia dos direitos da Primeira Infância - sem discriminação étnico-racial, de gênero, regional, religiosa, ideológica, partidária, econômica, de orientação sexual ou de qualquer outra natureza. (REDE NACIONAL PRIMEIRA INFÂNCIA, 2015).

Atualmente, o Grupo Gestor (2014-2016) é composto pelas seguintes organizações: Organização Não Governamental (ONG) Avante - Educação e Mobilização Social, Centro Internacional de Estudos e Pesquisas sobre a Infância (Ciespi/PUC-RJ), Centro de Pesquisa em Psicanálise e Linguagem (CPPL), Criança Segura, European Brain and Behaviour Society (EBBS), Fundação Maria Cecília Souto Vidigal, Fundação Abrinq, Instituto da Infância (Ifan), Instituto Alana, Organização Mundial para a Educação Pré-escolar (OMEP/BR) e Plan. 
É importante ressaltarmos o papel dessas instituições, pois elas têm atuado com abertura no campo da política educacional brasileira, como estratégia global dos reformadores empresariais da educação, financiado por bancos e tendo organismos internacionais à frente. Nota-se a vinculação de diferentes instituições de aparentes distintas matizes ideológicas na conformação da política educacional voltada para a Educação Infantil (vide Figura 2).

O Instituto Avisa Lá, integrante da elaboração dos documentos voltados para a Educação Infantil, como Indicadores de Qualidade na Educação Infantil (MINISTÉRIO DA EDUCAÇÃO; SECRETARIA DE EDUCAÇÃO BÁSICA, 2009a) e Monitoramento do Uso dos Indicadores de Qualidade na Educação Infantil (MINISTÉRIO DA EDUCAÇÃO; SECRETARIA DE EDUCAÇÃO BÁSICA, 201 1). tem como parceiros:

Figura 2 - Parceiros do Instituto Avisa Lá

Institucionais
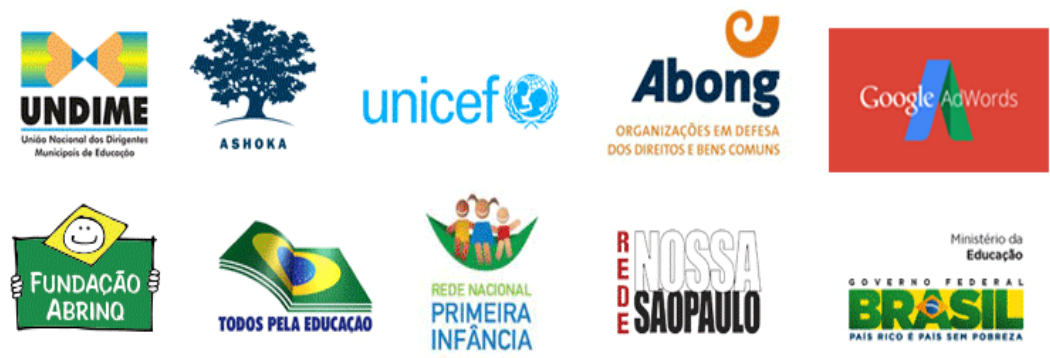

Trabalho
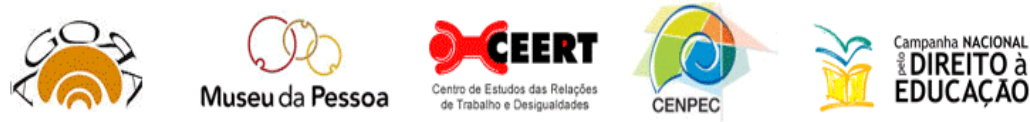

Apoiadores
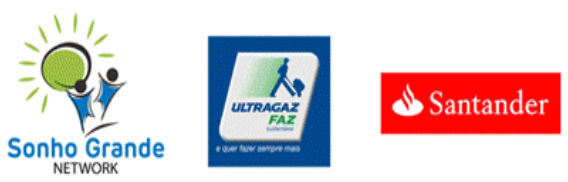

Deutsche Bank
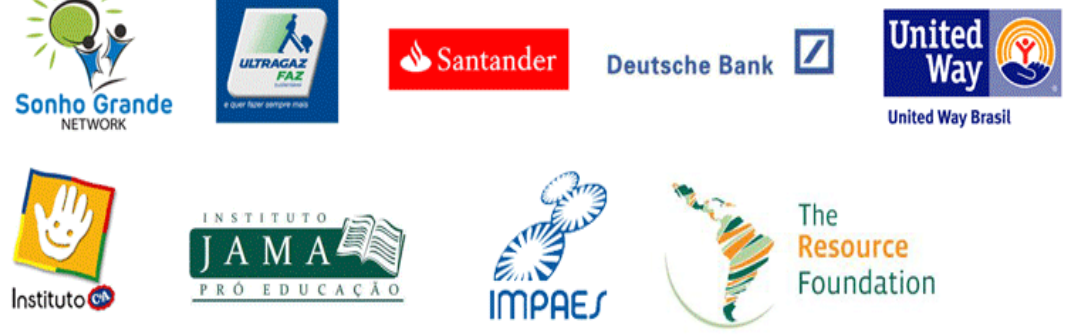

The

Resource

Foundation

Fonte: Instituto Avisa Lá (2016). 
Pela parceria com o Banco Santander e com o MEC, desde 201 1, o Instituto Avisa Lá tem desenvolvido o "Programa Educação Infantil", visando a uma maior integração "entre o poder público e a sociedade civil organizada em prol da efetiva mudança e transformação da realidade da educação infantil nos municípios onde está presente." (PROGRAMA EDUCAÇÃO INFANTIL, 2016). Portanto,

[...] o Programa Educação Infantil investe na atuação de técnicos das Secretarias de Educação com o objetivo de melhorar a qualidade do atendimento oferecido a crianças de 0 a 5 anos inseridas em creches e pré-escolas da rede pública dos municípios parceiros. [...] As consultoras do Avisa Lá desenvolvem projeto de formação nas áreas pedagógica e gestão para saúde e bem-estar visando à melhoria da qualidade da educação infantil. (PROGRAMA EDUCAÇÃ O INFANTIL, 2016).

A ideia difundida por instituições como essa sugere que a mudança na educação exige a conciliação do mercado com "justiça social". Para tanto, a estratégia mais atual tem sido a do empresariado "socialmente responsável", que além de participar e contribuir na organização das Políticas Públicas, forma diretamente representantes das secretarias de educação nos moldes propostos por eles, como indica o programa supracitado.

Sob esse viés, o foco das políticas tem se voltado com força para o discurso da melhoria da qualidade e da aprendizagem, o que, apesar de não ser um aspecto novo, apresenta um conjunto de características que precisam continuar a ser estudadas. Como afirmam Shiroma, Garcia e Campos (2011. p. 237),

[...] nos anos 2000, a noção de qualidade reaparece [...] como uma condição para a efetivação do direito à educação. [...] A educação de má qualidade precisa ser combatida por constituir um desperdício à nação, gerar custos e problemas pessoais e sociais. [...] Para que o direito à educação fosse efetivado era preciso assegurar permanência com qualidade. A grande diferença reside no fato de que a qualidade na perspectiva empresarial agora é reduzida aos resultados de aprendizagem, medidos através de tes- 
tes de rendimentos e pela avaliação das performances dos estabelecimentos escolares.

É no contexto de discussão acerca da necessidade de uma avaliação para a Educação Infantil que, em 2010, a Prefeitura da Cidade do Rio de Janeiro, em conjunto com o Instituto de Estudos do Trabalho e Sociedade (IETS), lançou o Manual de Uso do ASQ-3: Guia rápido para aplicação do ASQ-3 (PREFEITURA DO RIO DE JANEIRO, 2010), no qual, eficiência, eficácia, estratégia e domínios passam a ser palavras de ordem nos espaços de Educação Infantil.

A proposta da SAE era, a partir da "implementação-piloto" no Rio de Janeiro, adotar o ASQ-3 como avaliação nacional para a Educação Infantil. Entidades como a Associação Nacional de Pós-graduação e Pesquisa em Educação (Anped) e o Movimento Interfóruns do Brasil (Mieib) enviaram ao MEC e ao Conselho Nacional de Educação (CNE) uma moção de repúdio contra tal método avaliativo.

O GT 07 - Educação da criança de 0 a 6 anos manifesta seu REPÚDIO à adoção de políticas públicas em âmbito nacional, estadual e municipal de avaliação em larga escala do desempenho da criança de 0 até 6 anos de idade, por meio de questionários, testes, provas e quaisquer outros instrumentos, uma vez que tais procedimentos desconsideram a concepção de Educação Infantil e de avaliação presente na Lei de Diretrizes e Bases da Educação (Lei n. 9.394/96), nas Diretrizes Curriculares Nacionais para Educação Infantil (Resolução CNE/CEB n. 05 de dezembro de 2009) e nos Indicadores da Qualidade na Educação Infantil (2009). (OBSERVATÓRIO DA EDUCAÇÃO, 201 l).

Cláudia Costin (Secretária de Educação do Município do Rio de Janeiro no período de 2009 a 2014), para defender tal instrumento de avaliação, afirmou que "a creche agrega valor à criança que consegue se desenvolver conforme os padrões internacionais estabelecidos." (MINISTÉRIO DA EDUCAÇÃO; SECRETARIA DE EDUCAÇÃO BÁSICA, 201 l). Com isso, vincula o ensino público à qualidade quando articulado a uma suposta eficiência empresarial. Na mesma direção, o Deputado Federal Osmar Terra afirma que o Poder Público deve avaliar o mais cedo possível o desenvolvimento da primeira 
infância, pois, segundo ele, aguardar que a criança ingresse na escola para começar a monitorar sua evolução poderia dificultar a assistência. "A turma que é contra o método não quer ser avaliada. São os mesmos especialistas que criticam o Enem (Exame Nacional do Ensino Médio) e o Enade (Exame Nacional de Desempenho de Estudantes)." (TODOS PELA EDUCAÇÃO, 201 1).

A Fotografia 1 publicada no jornal $O$ Globo exemplifica a concepção empresarial de educação do município do Rio de Janeiro.

Fotografia l - Escola pública destinada à classe trabalhadora como linha de produção

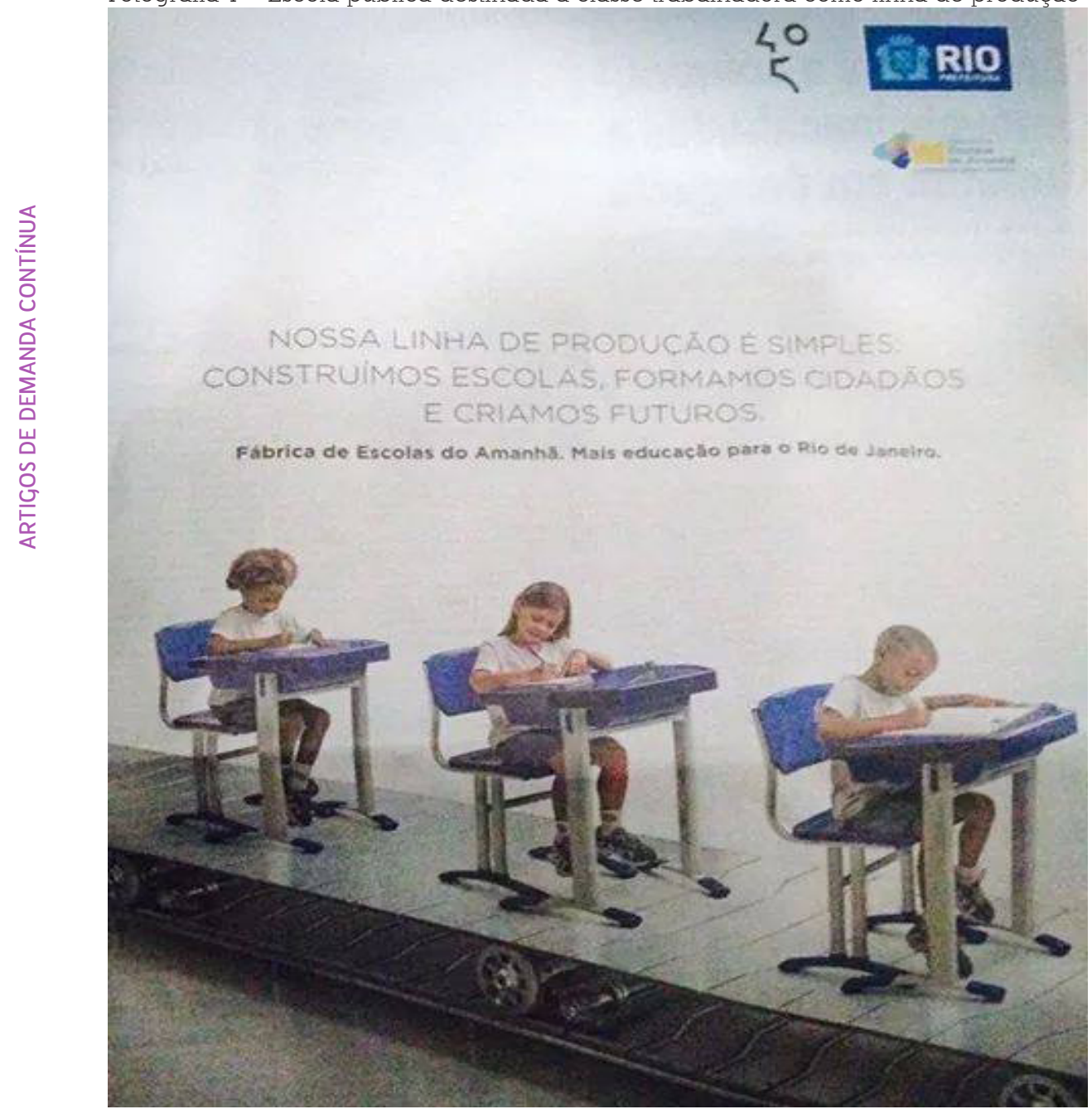

Fonte: $\bigcirc$ Globo (2014). 
Na mesma direção, em 2015, o então Ministro Roberto Mangabeira Unger, lançou pela SAE o documento Pátria Educadora (SECRETARIA DE ASSUNTOS ESTRATÉGICOS, 2015). Tal publicação não apresenta qualquer compromisso com dados, estudos ou referências. Trata-se de um texto que se propõe intervencionista, com base em opiniões e que tem como cerne a ideia de que a pobreza é um fenômeno individual. $\bigcirc$ ponto de partida apresentado no documento Pátria Educadora refere-se à necessidade de o ensino público se valer de uma suposta eficiência empresarial. Assim,

[...] nos últimos anos o Brasil viu grande número de experimentos na tentativa de melhorar os resultados do ensino público. Muitos destes experimentos seguiram lógica de eficiência empresarial, valendo-se de práticas como a fixação de metas de desempenho, a continuidade da avaliação, o uso de incentivos e métodos de cobrança, o acompanhamento e, quando necessário, o afastamento de diretores, a despolitização da escola de diretores e a individualização do ensino, especialmente para alunos em dificuldade. (SECRETARIA DE ASSUNTOS ESTRATÉGICOS, 2015, p. 5).

Portanto, reitera-se a necessidade de uma proposta de Política Pública baseando-se em experimentos que seguem a lógica empresarial. Isso não é novidade no Brasil. Em 1998 tivemos a aprovação da Lei n. 9.637, que dispõe sobre a qualificação de entidades como organizações sociais (BRASIL, 1998). Em 2007, com o Decreto n. 6.094 (BRASIL, 2007a), inclui-se nessa lógica o Plano de Metas Compromisso Todos pela Educação, política governamental que enfoca a participação de empresários, refletindo e propondo princípios e encaminhamentos para a educação pública.

O documento escrito por Mangabeira (SECRETARIA DE ASSUNTOS ESTRATÉGICOS, 2015) não apresenta referências explícitas à Lei n. 9.637/98 (BRASIL, 1998) ou ao TPE (BRASIL, 2007b), mas, ao afirmar que a política educacional deve ser baseada nos experimentos da lógica empresarial, reitera os encaminhamentos dados por tal legislação. Em vista disso, sob o viés do discurso do direito à educação, justificar-se-ia a privatização das escolas públicas. 
As proposições apresentadas no Pátria Educadora (SECRETARIA DE ASSUNTOS ESTRATÉGICOS, 2015) fundamentam-se em um sistema de responsabilização baseado em testes (para estudantes e professores), divulgação do desempenho da escola publicamente e recompensas e sansões. Evidencia-se, com isso, o caráter meritocrático das proposições, em que se tira o foco da desigualdade social, das contradições entre capital e trabalho, para uma suposta igualdade de condições via cidadania na escola destinada à classe trabalhadora.

Nesse contexto, a cidadania seria oferecida a todos pela universalização ou expansão da Educação Básica, cabendo ao mérito de cada um uma inclusão social. Nessas circunstâncias, o direito é apropriado sob a centralidade do indivíduo e suas competências, reforçando o pressuposto de que a pobreza seria um fenômeno individual.

Tais fundamentos têm como lógica o fato de que os "brasileiros pobres" podem ser resgatados dessa condição desde que adquiram capacitações socioemocionais, pois a falta destas é que impediriam a massa de alunos a "subir a escada das capacitações analíticas" (SECRETARIA DE ASSUNTOS ESTRATÉGICOS, 2015, p. 13). Para tanto, o enfoque parte de argumentos como talento, vocação, liberdade e democracia para embasar uma política que tem como objetivo o mérito. De acordo com o documento Pátria Educadora:

Todas as democracias do mundo enfrentam, na educação, a tensão entre os ideais de universalidade e igualdade de um lado, e a determinação de assegurar espaço aos talentos, de outro. A solução não está em impedir a variação do ensino e em impor a mediocridade em nome da democracia. Está em usar os programas especiais para subsidiar a transformação dos programas gerais. Está também em tomar medidas proativas para identificar vocações incomuns na massa de estudantes pobres e prepará-los para candidatar-se às escolas de referência e às sequências curriculares especiais. (SECRETARIA DE ASSUNTOS ESTRATÉGICOS, 2015, p. 16).

O texto reitera um modelo pedagógico que prioriza o treinamento ao indivíduo fora das relações sociais concretas (materiais e imateriais), com 
subordinação à lógica da economia competitiva empresarial, especialmente por um convencimento de que cada um é responsável por si, por sua trajetória e por suas escolhas. Tal falácia contribui, ainda, para a ampliação e a naturalização de mecanismos que reforçam a parceria público-privada, imputando um tipo de formação humana alijado da totalidade social.

\section{CONSIDERAÇÕES FINAIS}

Neste texto se propôs a discutir a obrigatoriedade da pré-escola no Brasil (Lei n. 12.796/2013) e a sua relação com o aprofundamento da participação do empresariado "socialmente responsável" como formulador de estratégias de implementação de políticas educacionais na Educação Infantil.

Vimos que para economistas que têm se dedicado aos estudos referentes à Educação Infantil, essa etapa da Educação Básica deve ser utilizada como uma das principais vias de diminuição das possibilidades de conflitos sociais pelo investimento nas "crianças pobres". Esse pensamento alinha-se às diretrizes dos organismos internacionais como o Banco Mundial (2002, p. 8), que afirmam a necessidade de focalização "na pré-escola como intervenção efetiva no desenvolvimento da primeira infância, especialmente para a melhoria da situação dos grupos mais pobres da população."

Nesse sentido, o papel dos organismos internacionais tem sido central na pactuação de metas e ações voltadas às políticas sociais — incluindo a Educação Infantil - como forma de se obter um suposto desenvolvimento sustentado com equidade social, além de utilizar o argumento de precaver a sociedade contra futuros gastos com assistência social (ORGANIZAÇÃO PARA A COOPERAÇÃO E DESENVOLVIMENTO ECONÔMICO, 2002).

Os argumentos advindos da economia e da neurociência têm reforçado as ideologias dominantes que divulgam concepções que garantem e legitimam a ordem estabelecida pelo capital, passando para o indivíduo a responsabilidade da desigualdade e não evidenciando suas origens sociais e históricas. 
Tais fundamentos têm como lógica o fato de que os "brasileiros pobres" podem ser resgatados dessa condição, mas, para isso, precisam de capacitações socioemocionais, pois a falta destas é que impediria a massa de alunos a "subir a escada das capacitações analíticas" (SECRETARIA DE ASSUNTOS ESTRATÉGICOS, 2015, p. 13). Para tanto, o enfoque parte de argumentos como talento, vocação, liberdade, democracia para embasar uma política que tem como objetivo o mérito.

Constatamos que as parcerias público-privadas, na formulação e execução de políticas públicas para a Educação Infantil, fazem parte de uma lógica mercadológica que tem encontrado terreno fértil na educação das crianças pequenas. Tal concepção tem tido o protagonismo do empresariado organizado para influir nas políticas públicas de educação, o que pode sinalizar mais um mecanismo de retrocesso à luta pela educação pública como direito social e formação humana.

Por essa razão é preciso compreender as condições objetivas e subjetivas que têm mantido as relações de perpetuação desse pensamento, bem como as mediações dessa relação que é dinâmica e contraditória na lógica do modo de produção capitalista. A plena formação humana e sua plena realização como espécie é uma utopia em construção, assim também nos parece ser o pleno direito às condições de igualdade e qualidade.

\section{REFERÊNCIAS}

ANDRÉ, S.; COSTA, A. C. G. DA. Educação para o desenvolvimento humano. São Paulo: Saraiva: Instituto Ayrton Senna, 2004.

ARAÚJO, A. P. de (Coord.). Aprendizagem infantil: uma abordagem da neurociência, economia e psicologia cognitiva. Rio de Janeiro: Academia Brasileira de Ciências, 2011 .

BANCO MUNDIAL. Brasil desenvolvimento da primeira infância: foco sobre o impacto das pré-escolas. Relatório n. 22841-BR, Região da América Latina e Caribe, 2002. Disponível em: <http:// siteresources.worldbank.org/BRAZILINPOREXTN/Resources/ 381 1166 - 1 185895645304/4044168-1 186326902607/08Portugues.pdf > . Acesso em: 30 jun. 2012. 
BRASIL. Constituição da República Federativa do Brasil. 17. ed. Brasília, DF: Câmara dos Deputados: Centro de Documentação e Informação, 1988.

BRASIL. Decreto n. 6.094, de 24 de abril de 2007. Dispõe sobre a implementação do Plano de Metas Compromisso Todos pela Educação, pela União Federal, em regime de colaboração com Municípios, Distrito Federal e Estados, e a participação das famílias e da comunidade, mediante programas e ações de assistência técnica e financeira, visando a mobilização social pela melhoria da qualidade da educação básica. Diário Oficial da União, 25 abr. 2007a.

BRASIL. Decreto n. 6.253, de 13 de novembro de 2007. Dispõe sobre o Fundo de Manutenção e Desenvolvimento da Educação Básica e de Valorização dos Profissionais da Educação - FUNDEB, regulamenta a Lei 1 l. 494, de 20 de junho de 2007, e dá outras providências. Diário Oficial da União, Brasília, DF, 14 nov. 2007b.

BRASIL. Emenda Constitucional n. 53, de 19 de dezembro de 2006. Dá nova redação aos arts. $7^{\circ}, 23,30,206,208,211$ e 212 da Constituição Federal e ao art. 60 do Ato das Disposições Constitucionais Transitórias. Diário Oficial da União, Brasília, DF, 20 dez. 2006.

BRASIL. Emenda Constitucional n. 59, de 11 de novembro de 2009. Acrescenta $\S 3^{\circ}$ ao art. 76 do Ato das Disposições Constitucionais Transitórias para reduzir, anualmente, a partir do exercício de 2009, o percentual da Desvinculação das Receitas da União incidente sobre os recursos destinados à manutenção e desenvolvimento do ensino de que trata o art. 212 da Constituição Federal, [...] com a inserção neste dispositivo de inciso VI. Diário Oficial da União, Brasília, DF, 12 nov. 2009.

BRASIL. Lei n. 1 1.494, de 20 de junho de 2007. Regulamenta o Fundo de Manutenção e Desenvolvimento da Educação Básica e de Valorização dos Profissionais da Educação - FUNDEB, de que trata o art. 60 do Ato das Disposições Constitucionais Transitórias; altera a Lei no 10.195, de 14 de fevereiro de 2001; revoga dispositivos das Leis nos 9.424, de 24 de dezembro de 1996 , 10.880, de 9 de junho de 2004, e 10.845, de 5 de março de 2004; e dá outras providências. Diário Oficial da União, Brasília, DF, 22 jun. 2007c.

BRASIL. Lei n. 12.796, de 04 de abril de 2013. Altera a Lei n. 9.394, de 20 de dezembro de 1996, que estabelece as diretrizes e bases da educação nacional, para dispor sobre a formação dos profissionais da educação e dá outras providências. Diário Oficial da União, Brasília, DF, 05 abr. 2013. 
BRASIL. Lei n. 9.394, de 20 de dezembro de 1996. Estabelece as Diretrizes e Bases da Educação Nacional. Diário Oficial da União, Brasília, DF, 23 dez. 1996.

BRASIL. Lei n. 9.637, de 15 de maio de 1998. Dispõe sobre a qualificação de entidades como organizações sociais, a criação do Programa Nacional de Publicização, a extinção dos órgãos e entidades que menciona e a absorção de suas atividades por organizações sociais, e dá outras providências. Diário Oficial da União, Brasília, DF, 18 maio 1998.

CAMPOS, M. M. Educação infantil: o debate e a pesquisa. Cadernos de Pesquisa, Fundação Carlos Chagas, São Paulo, n. 101, p. 1 13-127, jul. 1997. Disponível em: <http://www.fcc.org.br/pesquisa/publicacoes/cp/arquivos/253.pdf>. Acesso em: 06 dez. 2004.

COSTIN, C.; BANERJI, A.; EVANS, T. G. Prefácio. In: DENBOBA, A. et al. (Org.). Intensificando o desenvolvimento da primeira infância: investindo na primeira infância com grandes retornos. Banco Mundial: Fundação Maria Cecília Souto Vidigal: Children's Investment Fund Foundation (CIFF), 2014. Disponível em: <http://www.fmcsv.org.br/pt-br/acervo-digital/Paginas/ intensificando-o-desenvolvimento-da-primeira-infancia.aspx > . Acesso em: 19 abr. 2015 .

CUNHA, F.; HECKMAN, J. Capital Humano In: ARAÚJO, A. P. de (Coord.).

Aprendizagem infantil: uma abordagem da neurociência, economia e psicologia cognitiva. Rio de Janeiro: Academia Brasileira de Ciências, 2011.

DAVIES, N. Fundeb: a nova redenção da educação? Educ. Soc., Campinas, vol. 27, n. 96 - Especial, p. 753-774, out. 2006. Disponível em: < http://www. folhadirigida.com.br/htmls/hotsites/suplemento_2006/Cad_03/pag_35.htm > . Acesso em: 08 out. 2010.

DENBOBA, A. et al. Intensificando o desenvolvimento da primeira infância: investindo na primeira infância com grandes retornos. Banco Mundial: Fundação Maria Cecília Souto Vidigal: Children's Investment Fund Foundation (CIFF), 2014. Disponível em: < http://www.fmcsv.org.br/pt-br/acervo-digital/ Paginas/intensificando-o-desenvolvimento-da-primeira-infancia.aspx>. Acesso em: 19 abr. 2015.

DI PIERRO, M. C. Descentralização, focalização e parceria: uma análise das tendências nas políticas públicas de educação de jovens e adultos. Educação e Pesquisa, v. 27, n. 2, p. 321-337, 2001. Disponível em: <http://www.scielo. br/scielo.php?pid =S1517-97022001000200009\&script $=$ sci_arttext $>$. Acesso em: 02 jun. 2006. 
FRIGOTTO, G. Capital humano. In: PEREIRA, I. B.; LIMA, J. F. (Org.). Dicionário da educação profissional em saúde. 2. ed. rev. e ampl. Rio de Janeiro: EPSJV, 2009. Disponível em: <http://www.epsjv.fiocruz.br/dicionario/ Dicionario2.pdf $>$. Acesso em: 07 jun. 2014.

FRIGOTTO, G. (Org.). Educação e crise do trabalho: Perspectivas de final de século. Petrópolis: Vozes, 1998.

FUNDAÇÃO MARIA CECILIA SOUTO VIDIGAL. O que fazemos. Disponível em: <http://www.fmcsv.org.br/pt-BR/o-que-fazemos/Paginas/default.aspx> . Acesso em: 07 jun. 2014.

GARCIA, R. C. Para além da "inclusão": crítica às políticas educacionais contemporâneas. In: EVANGELISTA, O. (Org.). O que revelam os slogans na política educacional. Araraquara: Junqueira \& Marin, 2014.

GOES, F; ROSAS, R. Ensino de baixa qualidade pode limitar crescimento, diz ganhador de Nobel. Valor Econômico, São Paulo, 28 ago. 2016.

GRAMSCI, A. Cadernos do cárcere. Rio de Janeiro: Civilização Brasileira, 2013. v. 1 .

HARVEY, D. 17 contradições e o fim do capitalismo. São Paulo: Boitempo, 2016.

HÖFLING, E. de M. Estado e políticas (públicas) sociais. Cadernos Cedes, ano 21, n. 55, nov. 2001. Disponível em: <http://scielo.br/pdf/ccedes/ v2 ln55/5539>. Acesso em: 15 nov. 2014.

LAMARE, F. F. Contradições na concepção de formação humana nas políticas de Educação Infantil no Brasil: o que revelam os documentos do período de 2003 a 2010. 2016. 233 p. Tese (Doutorado em Políticas Públicas e Formação Humana)-Universidade do Estado do Rio de Janeiro, Rio de Janeiro, 2016.

MARX, K.; ENGELS, F. A ideologia alemã: crítica da mais recente filosofia alemã em seus representantes Feurbach, B. Bauer e Stirner, e o socialismo alemão em seus diferentes profetas (1845-1846). São Paulo: Boitempo, 2007.

MINISTÉRIO DA EDUCAÇÃO; SECRETARIA DE EDUCAÇÃO BÁSICA. Indicadores de qualidade na educação infantil. Brasília, DF: MEC: SEB, 2009a.

MINISTÉRIO DA EDUCAÇÃO; SECRETARIA DE EDUCAÇÃO BÁSICA. Monitoramento do uso dos indicadores de qualidade na educação infantil. Brasília, DF: MEC: SEB, 2011. 
MINISTÉRIO DA EDUCAÇÃO; SECRETARIA DE EDUCAÇÃO BÁSICA. Política de educação infantil no Brasil: Relatório de avaliação. Brasília, DF: MEC: SEB: Unesco, 2009b.

NERI, M. (Coord.). Educação da primeira infância: evidências brasileiras. Rio de Janeiro: FGV, 2005. Disponível em: <http://www.mprs.mp.br/areas/ infancia/arquivos/primeirainfanciafgv.pdf>. Acesso em: 23 abr. 2015.

\section{OBSERVATÓRIO DA EDUCAÇÃO. Pesquisadores da educação infantil cri-} ticam ideia de avaliação em programa para primeira infância do governo federal. São Paulo, 2011 . Disponível em: < http://www.observatoriodaeducacao.org.br/index.php/sugestoes-de-pautas/48-sugestoes-de-pautas/ 1103 -pesquisadores-da-educacao-infantil-criticam-ideia-de-avaliacao-em-programa-para-primeira-infancia-do-governo-federal>. Acesso em: 20 ago. 2014.

\section{ORGANIZAÇÃO PARA A COOPERAÇÃO E DESENVOLVIMENTO ECONÔMI-} $\mathrm{CO}$. Educação e cuidado na primeira infância: grandes desafios - educaÇão e competência. Brasília, DF: Unesco: Ministério da Saúde, 2002. Disponível em: <http://unesdoc.unesco.org/images/0013/001362/136283POR. pdf > . Acesso em: 20 abr. 2014.

PREFEITURA DO RIO DE JANEIRO. Manual de Uso do ASQ-3: guia rápido para aplicação do ASQ-3. Rio de Janeiro: IETS, 2010.

\section{PROGRAMA EDUCAÇÃO INFANTIL. Sobre o programa educação infantil} [S.l.]: Instituto Avisa Lá; Santander. Disponível em: <http://www.programaeducacaoinfantil. org/sobre-o-programa.html>. Acesso em: 19 fev. 2016.

RAMOS, M. N. A pedagogia das Competências e a Psicologização das Questões Sociais. Boletim Técnico do SENAC, v. 27, n. 3, set./dez. 2001. Disponível em: <http://www.senac.br/BTS/273/boltec273c.htm>. Acesso em: 13 jun. 2015.

REDE NACIONAL PRIMEIRA INFÂNCIA. Quem somos. Disponível em: $<$ http://primeirainfancia.org.br/quem-somos/>. Acesso em: 13 jun. 2015.

SANTOS, D. D. dos; PORTO, J. A.; LERNER, R. O impacto do desenvolvimento na primeira infância sobre a aprendizagem. Comitê Científico Núcleo Ciência pela Infância, 2014. Disponível em: <http://www.ncpi.org.br/ produtos/textos/>. Acesso em: 25 abr. 2015.

SECRETARIA DE ASSUNTOS ESTRATÉGICOS. Pátria educadora: a qualificação do ensino básico como obra de construção nacional. Brasília, DF, 2015. 
SHIROMA, E. O.; GARCIA, R. M. C.; CAMPOS, R. F. Conversão das "almas" pela liturgia da palavra: uma análise do discurso do movimento Todos Pela Educação. In: BALL, S. J.; MAINARDES, J. (Org.). Políticas educacionais: questões e dilemas. São Paulo: Cortez, 2011.

SOUSA JUNIOR, L. de. FUNDEB: novo fundo, velhos problemas. In: REUNIÃO DA ASSOCIAÇÃO NACIONAL DE PÓS-GRADUAÇÃO E PESQUISA EM EDUCAÇÃO, 30., 2007, Caxambu. Anais... Caxambu, 2007. Disponível em: $<$ http://www.anped.org.br/reunioes/30ra/ trabalhos/GT05-309l--Int.pdf > . Acesso em: 02 nov. 2008.

TODOS PELA EDUCAÇÃO. Educadores questionam avaliação: criado nos Estados Unidos, exame para crianças de até cinco anos de idade em teste no Rio pode ser aplicado em todo o Brasil. Zero Hora, 2011 . Disponível em: <http://www.todospelaeducacao.org.br/educacao-na-midia/indice/20721/ educadores-questionam-avaliacao>. Acesso em: 25 jan. 2016.

UNESCO. Declaração mundial sobre educação para todos. Plano de ação para satisfazer as necessidades básicas de aprendizagem. Aprovada pela conferência mundial sobre educação para todos. Jomtien, 1998. Disponível em: <http://unesdoc.unesco.org/images/0008/000862/08629l por.pdf> . Acesso em: 8 out. 2015.

WEBER, D. Educação à Brasileira. Depois de 4 anos, a escola não recupera mais. Jornal O Globo, 13 dez. 2009. Entrevista concedida a Aloísio Araújo. Disponível em: <http://oglobo.globo.com/blogs/educacao/ posts/2009/12/15/depois-de-4-anos-escola-nao-recupera-mais-250279. asp >. Acesso em: 20 abr. 2015.

Recebido em: 18 de julho de 2017

Aceito em: 21 de junho de 2018

Endereço para correspondência: Avenida Brasil, 4365, Manguinhos, $21040-$ 900, Rio de Janeiro, Rio de Janeiro, Brasil; flavia.lamare@fiocruz.br 
